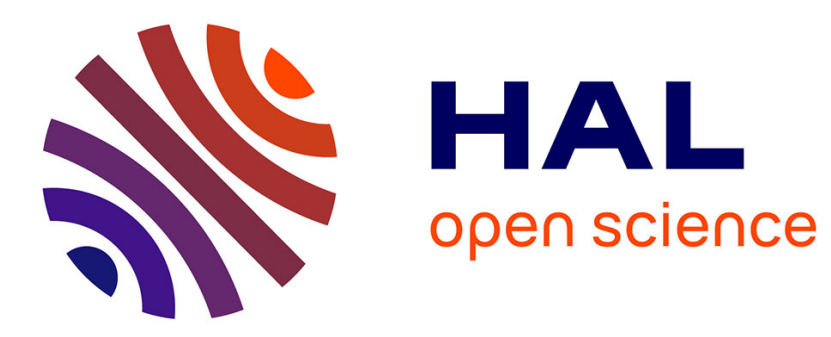

\title{
\#TheDay: Triggering User Generated Videos in Participatory Media Productions
}

Sandy Claes, Maarten Wijnants, Chaja Libot, Rik Bauwens

\section{To cite this version:}

Sandy Claes, Maarten Wijnants, Chaja Libot, Rik Bauwens. \#TheDay: Triggering User Generated Videos in Participatory Media Productions. 17th IFIP Conference on Human-Computer Interaction (INTERACT), Sep 2019, Paphos, Cyprus. pp.409-417, 10.1007/978-3-030-29381-9_26 . hal02544555

\section{HAL Id: hal-02544555 \\ https://hal.inria.fr/hal-02544555}

Submitted on 16 Apr 2020

HAL is a multi-disciplinary open access archive for the deposit and dissemination of scientific research documents, whether they are published or not. The documents may come from teaching and research institutions in France or abroad, or from public or private research centers.
L'archive ouverte pluridisciplinaire HAL, est destinée au dépôt et à la diffusion de documents scientifiques de niveau recherche, publiés ou non, émanant des établissements d'enseignement et de recherche français ou étrangers, des laboratoires publics ou privés.

\section{(c)(1)}

Distributed under a Creative Commons Attribution| 4.0 International License 


\title{
\#TheDay: Triggering User Generated Videos in Participatory Media Productions
}

\author{
Sandy Claes $^{[1]}$, Maarten Wijnants ${ }^{[2]}$, Chaja Libot ${ }^{[1]}$ Rik Bauwens $^{[1]}$ \\ ${ }^{1}$ VRT Innovation, Brussels, Belgium \\ \{Sandy.claes, chaja.libot, rik.bauwens@vrt.be\} \\ ${ }^{2}$ Hasselt University - tUL, Expertise Centre for Digital Media, Diepenbeek, Belgium \\ \{maarten.wijnants@uhasselt.be\}
}

\begin{abstract}
Traditional media such as television are increasingly adopting interaction logic as a way to engage viewers. In this paper, we report on the design of a smartphone application that facilitates the participatory production process of \# TheDay, a two-minute item in an infotainment TV show, which is broadcasted twice a week on national television. \#TheDay leverages a co-creation approach as it allows viewers to submit and discuss self-produced video content, this way empowering them to share their take on topics imposed by TV producers. We report on \#TheDay's eight-month deployment. Through a mixed methods approach, we learn how the TV producers succeeded in triggering viewer interaction, also on a long-term. From our findings, we distill three considerations for the design of interactive applications that support professional producers in deploying participatory forms of media production with sustained user commitment.
\end{abstract}

Keywords: Co-creation, participatory TV, User-Generated Content (UGC), User-Generated Video (UGV), Social Media, evaluation, engagement

\section{Introduction and Background}

Given the increasing popularity of social media, television broadcasters started to embrace social media logic in multiple ways in an attempt to stay relevant [3]. In particular, the logic of programmability includes the transformation of one-way traffic, which is typical for television consumption, to two-way communication between users and producers - a process that affected both the technological and social mediation of content [3]. Merging such User-Generated Content (UGC) with professionally produced video has already been found to form one particular way to enhance audience engagement [8]. Yet we know little about how interaction design facilitates media producers to engage viewers in the co-creation process of media productions [6]. Furthermore, participatory media productions are often studied in the context of specific niches like interactive documentaries (e.g., [11]), interactive film (e.g., [1]) or online music experiences [5], yet in general they are still exceptions in the media landscape [9].

Our research is based on \# The Day, a two-minute item in an infotainment TV show that is broadcasted twice a week during prime time on national television in Flanders, 
Belgium. \#TheDay invites viewers of the show to share specific audiovisual contributions that relate to the trending topics of that day via a smartphone application. The targeted "assignments" in relation to the interaction design of the application facilitate responses in the form of both text (i.e., users can chat with TV producers) and UserGenerated Video (UGV). We hypothesize that exactly this focus on conversational interactions contributes to the engagement of users in submitting (audiovisual) content.

\# TheDay has been included in the broadcast schedule for about a full year. To address our research question, we evaluate the objective data that has been captured in this time frame and complement this data with qualitative insights yielded by conducting semi-structured interviews with both contributing users of the application and professional producers of \# TheDay. In particular, we study the (reasons for) engagement of contributing users, especially those who participated multiple times in generating audiovisual content for the television show and offset these user engagement incentives against the viewpoint of professional producers.

Our primary research contribution, then, is a formulation of three pragmatic considerations for designing interactive (smartphone) applications that support media professionals to trigger user generated audiovisual materials.

\section{Design}

\# TheDay is part of the TV show "Iedereen Beroemd" (translated as "Everybody Famous") of public broadcaster VRT (in Flanders, Belgium), which is aired every day of the workweek during prime time (i.e., immediately after the evening news bulletin, around 7.30 PM). The show aims to present the viewpoint of 'John Doe' on current events, in a lightweight fashion. \#TheDay occurs each Tuesday and Thursday and includes a call-to-action for viewers to install a dedicated \# TheDay smartphone application in order to send footage of "their day" to the producers of the show.

The assignment-based approach of \# The Day affords viewers the opportunity to cocreate stories with the TV producers, while at the same time granting the latter stakeholder group tighter control over the storyline and facilitating the "tying together" of the incoming footage in a meaningful way. The design of the \#TheDay smartphone front-end is driven by three requirements elicited from the producers. First, as the show targets a broad audience with divergent demographics and backgrounds, the application should be easy to use. Secondly, the application should grant viewers full creative freedom when creating video footage. The producers aim to receive footage with a 'DIY aesthetic' in order to highlight the sincerity and authenticity of the viewers' contributions in the final edit (i.e., the montage that is aired on TV). Producers also envision this aesthetic to connect to existing social media practices such as adding graphic elements (e.g., emojis). Therefore, they requested not to work with rigid templates or overlay instructions, in contrast to comparable UGC systems (e.g., [7]). Instead, as third requirement, viewers should be able to contact the producers for guidance.

Professional producers expressed the wish that the editorial interface should enable them to immediately consult the incoming UGV footage and to directly communicate 
with contributing users. Secondly, the system should allow the production team members to label the footage before sending it to post-production to enable a quick and efficient workflow.

\subsection{User flow}

When opening the smartphone application for the first time, viewers are presented with a login screen where they can create a user profile for the online platform of VRT or $\log$ in with an existing one. Because of the General Data Protection Regulation (GDPR) in Europe that went in effect on May 25, 2018, the application can only be accessed by registered users, which already forms a threshold for viewers to open and inspect the application [4]. However, the use of connected user profiles allows the producers to check whether the contributing user is over 18 years old and has given his or her consent to appear on television. Then, the first screen presents an overview of open assignments (see Figure 1.1) and a camera button (below) that immediately allows users to select and upload video footage from their smartphone media gallery. When uploaded, users receive a thank you response via a Conversational User Interface (CUI), as shown in Figure 1.3. Videos can also be uploaded from within this screen, to grant users the option to weave their footage into a conversation with the producers. If not immediately uploading video footage, users are able to access their chat conversations and other settings via an overlay menu or via a chat bubble button in the top right of the screen (see Figure 1.2).

The design rationale of the application mainly focused on establishing conversations, which were a requirement for both the professional producers' and users' end of the application. Therefore, second (and multiple)-time users enter the application via a conversational user interface (see Figure 1.3), after they clicked a push notification with the assignment(s) of that day. CUIs allow users to interact with producers in their natural language (text). CUIs can support interactions with another human or with a chatbot (simple software program). This design was introduced to lower the barrier for users to engage with the application in order to chat with the producers. This approach builds upon the sense of belonging to the media production team that is already triggered by user generated visual materials [11], which is further augmented via the conversational design. It is also a way for the producers to give feedback to users, on their submitted audiovisual content as well as on their filming techniques.

The editorial interface then enables producers to request users to contextualize their footage or to ask for additional footage via the CUI. Chat messages that announce the assignment(s) or thank the users after submitting footage are sent automatically (by a chatbot). Personal chat messages issued by producers are signed with their real name, and every user that submits a video receives such a personal message to indicate whether their footage has been included in the TV item or not. The professional producers also receive an overview of all uploaded videos in this editorial tool. Each incoming video is examined and labeled by a professional producer and, if deemed usable, is sent to the broadcaster's ingest system for integration in their post-production environment, where the final edit is produced. Then, when the submission period ends 
(i.e., approximately 1.5 hours before broadcast, at $6 \mathrm{PM}$ ), each contributing user receives a message with a link to the final edit as it will be broadcasted later that day.
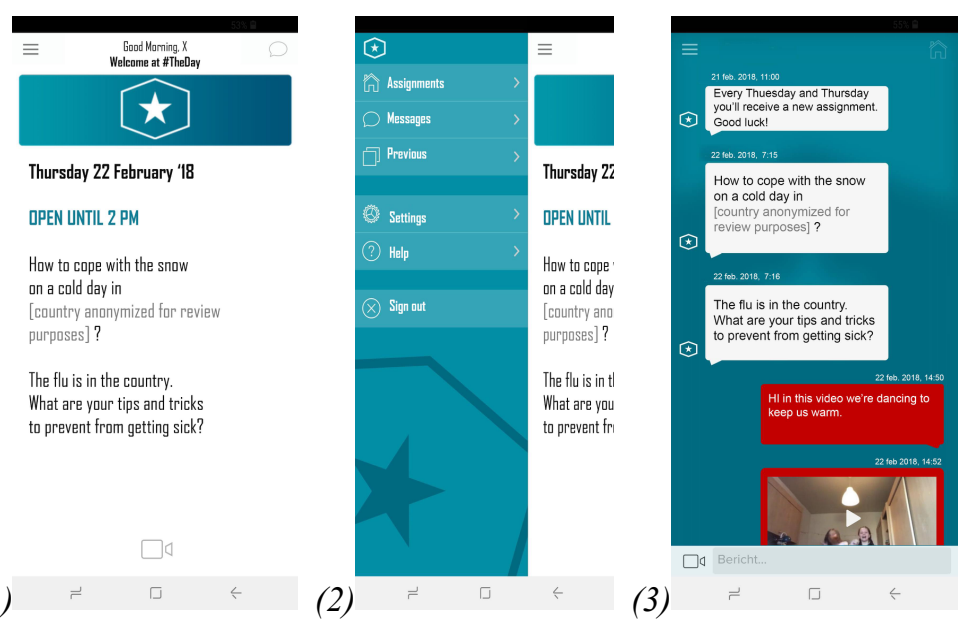

Fig. 1. User flow of the \#TheDay smartphone application: (1) Open assignments, (2) Overlay menu, (3) Chat messages with the TV production team.

\section{Study}

The evaluation focused on how the \#TheDay application, and the CUI specifically, facilitates user engagement. The item was first aired March 6, 2018, after which it ran twice a week until June 30, 2018. After a two-month summer break, \#TheDay launched again on September 4, 2018 with an average of 701.212 viewers [2] that day and ran until December 27, 2018. During these two television seasons, we logged all interactions of both viewers and producers with the application via Google Analytics. We managed a mixed methods approach, combining quantitative data with qualitative insights from semi-structured interviews with frequently contributing users $(\mathrm{N}=7)$ and professional producers $(\mathrm{N}=3)$.

In total, 4501 users $^{1}$ installed the application in the analyzed period of approximately eight months, of which 2025 were female. Most users were relatively young, i.e. 18,4 percent of the female users were between 18 and 24 years old versus 10,4 percent of men. The gender distribution is more evenly spread in the age category of 35-44 years old ( $13 \%$ female versus $12 \%$ male), while men even take the upper hand in older age groups (i.e., $>44$ y.o., 9\% female versus 13\% male). Finally, there exists a clear inversely proportional relationship between application installation and age (i.e., lower installation rate in older age ranges), which is a strong indicator that the application and the \#TheDay concept appeals mostly to younger people. Users sent 3979 messages in

1 We use the term user to refer to someone who has installed and opened the \#TheDay smartphone app without necessarily contributing UGV. People who uploaded at least one video via the app are referred to as contributing users. 
total, of which 944 text messages (in contrast to 3035 video messages). Most users thus submitted their video contributions without any additional text.

\subsection{Study Participants}

On December 28, 2018, a call for participation was administered via the smartphone application, asking users to complete a concise digital survey. The survey covered topics like users' assessment of the witnessed degree of freedom, the guidance provided by producers, their completed assignment count and their motivation for contributing. 14 Users completed the survey; from this pool of users, 10 were contacted for a followup interview. Our main participant selection criterion here was "to have at least a minimal level of \# TheDay experience", i.e. contributing UGV more than twice and having more than 2 months of experience with the application. 7 Participants voluntarily accepted the invitation. The semi-structured interviews occurred via telephone and lasted approximately 10 minutes. In addition, we organized semi-structured interviews with three professional \#TheDay producers who are responsible for identifying interesting topics, formulating assignments, contacting and coaching contributing users and giving directions to the post-production team. These interviews lasted approximately 30 minutes each. For both the user and producer interviews, resulting data were transcribed per interview and then divided into quotes. Via a grounded theory approach, two researchers independently coded and categorized these quotes [9], and then reached consensus on their individual codes. The participant profiles for both our user and producer stakeholder groups are summarized in Table 1.

Table 1. Overview of study participants who are representative of long-term engaged users and professional producers, respectively.

\begin{tabular}{l|l|l|l|l|l} 
User ID & Age & Gender & $\begin{array}{l}\text { Self-reported num- } \\
\text { ber of participations }\end{array}$ & $\begin{array}{l}\text { Date of app } \\
\text { installation }\end{array}$ & $\begin{array}{l}\text { Member of 'frequent user } \\
\text { pool' (see Section 4.3) }\end{array}$ \\
\hline U1 & 41 & F & $4-5$ & Nov 2018 & no \\
\hline U2 & 32 & M & $6-7$ & May 2018 & no \\
\hline U3 & 21 & M & Every week & May 2018 & yes \\
\hline U4 & 24 & M & 3 & May 2018 & no \\
\hline U5 & 40 & F & $20-25$ & June 2018 & no \\
\hline U6 & 25 & M & Every (two) week(s) & May 2018 & yes \\
\hline U7 & 26 & F & Every time & May 2018 & yes \\
\hline Producer ID & \multicolumn{2}{|l}{ Gender } & Role as professional producer & \\
\hline P1 & \multicolumn{2}{|l|}{ M } & Chief editor \# TheDay & \\
\hline P2 & \multicolumn{2}{|l|}{ F } & Editor \#TheDay & \\
\hline P3 & \multicolumn{2}{|l}{ M } & Chief editor of hosting infotainment TV show
\end{tabular}




\section{$4 \quad$ Results and Discussion}

\subsection{Viewer and Producer Motivation}

In \#TheDay's first season, the application was mostly opened when a new assignment was released, i.e. on Tuesdays and Thursdays, which was also the moment for sending text and video messages. In the second season, this pattern was more spread over several days, which overlapped with the producers' strategic decision to deploy the assignments earlier than the broadcast date. This decision was informed by feedback from users who sent this spontaneously via the CUI. Such immediate and direct feedback from their audience was a novel experience for the participating producers. In specific, those users mentioned the time constraint to be a factor for disengagement. Therefore, in the beginning of the second season, producers adapted their approach to send out (most) assignments a day earlier (i.e., on the evening before broadcast).

U4 expressed to open the application in order to read the assignments as they triggered him to reflect on current topics and stay up-to-date, as he does not have the time or interest to explore the news. In that sense, the creative challenges posed by \#TheDay succeeded in engaging him to explore relevant topics. Furthermore, U2 initially participated in \#TheDay as he believed it could be a platform for his activist agenda. Although he did not submit footage concerning such an agenda, he appreciated learning about how to deploy media. U6 is a journalist by profession and stated how creating \# TheDay footage connects to his daily work in a different, more relaxed way. In this context, U6 mentioned how he enjoys giving his footage 'out of his hands' and to discover what the professional producers did with it. The openness of the assignments was also found to foster creativity (i.e., being able to fulfill an assignment without imposed constraints, mentioned by U1, U4, U6), which most participants mentioned to be crucial in their motivation to continue sending in content.

From the production side, P2 recalled one particular experiment in which UGV contributed by different fans of a specific professional cyclist was mixed with professional footage from the sports department of the broadcaster. The final edit thus combined objective and subjective coverage of the involved cyclist, which P2 felt resulted in a story that was exciting and emotional. This experiment hints that UGV can be a valuable means to complement professional coverage in order to tell a compelling story. Furthermore, the conversational approach with individual users encouraged producers to reflect on their pre-composed storyline, which might support them in the editing process and even in identifying new stories and assignments [5], a process that might not occur when communicating to a group of users.

Design guideline \#1: Initial engagement was triggered by intrinsic motivation factors such as curiosity and learning, which should be supported by the interaction design of the application. The conversational interface seemed to lower barriers to discuss the production process of the television item, which also supported the producers in learning how to trigger user generated content. 


\subsection{Social Aspects}

Four user participants referred to the social aspect of completing assignments together with others as key for their motivation and long-term engagement. U7, who has participated in every assignment thus far, used to shoot footage during her lunch break together with two colleagues. When one of these colleagues left their company, all three continued participation yet added a competitive element, in the sense that the former colleague now competes with U7 (and the remaining colleague) for the 'best' footage (i.e., the footage that makes it to the final edit). U1 similarly mentioned she is currently planning to execute assignments together with her colleagues. U1 also reported how she sees her participation as a collaborative effort, generating footage together with other people, including her children. U6 claimed to initiate the participation yet always collaborates with fellow students to make footage. U6 also mentioned how the participatory assignments "seem to bring people together" by giving the example of receiving several text messages from people who he had not spoken to for more than 5 years after appearing on \# TheDay. U1 mainly repeated participation on request of her children. They enjoy the process of pondering what to film, the actual filming and the reward of seeing their contribution being included in the TV show. U5 similarly reported she engages with the assignments in order to share an activity with her children.

Design guideline \#2: Integrate collaboration or even competition amongst users when designing an application for triggering user generated videos. We learned how the social aspect of working together on an assignment caused contributing users to be engaged to repeatedly co-create. Often, they referred to this collaborative aspect in a competitive way, e.g. against colleagues, family and friends, or other unknown users.

\subsection{Personal and Automated Conversations}

The personal contact between users and professional producers that was facilitated via the CUI was found to contribute positively to the collaborative aspect of \# TheDay. P2 felt she has built relationships with several contributing users who she learned to know over time, through their conversations and submitted video footage. This led to a 'pool of frequent users', i.e. 20 participants (see also Table 1), who the producers trust to deliver promising UGV. When needed, the producers contact these viewers with targeted (yet voluntary) requests to produce additional footage. U6 and U7 reported that receiving such requests are exciting and enticed a sense of belonging, yet they also felt annoyed if they could not oblige due to time or other constraints.

$\mathrm{U} 1, \mathrm{U} 2, \mathrm{U} 4$ and $\mathrm{U} 5$ reported not to have engaged in such chat conversations with the producers. However, they expressed to have personal contact with the producers, which might indicate the automatic contact supports this sense of belonging. In general, the chatbot was well-received by all of our participating users as it provided them initial confirmation and they were aware these messages were automatically generated (as the messages of producers were signed by name). Two producers, however, mentioned how this is feasible for the small frequent user pool, yet they envision this to be too time consuming when scaling up. Although P1 and P2 were initially weary of integrating a 
chatbot to discuss the user generated videos with users (i.e. in the design phase), through their actual experience with the automated messages, they saw opportunities to support their work.

Design guideline \#3: When designing for participatory media productions, the interaction design should establish personal conversations. Indeed, we learned how messages from the producers were key for building a lasting relationship with the users and sparked a sense of belonging. In fact, even without 'real' conversations, the ability to have contact supported the feeling of belonging to the production team.

\section{$5 \quad$ Conclusions and Future Work}

We have presented the design and evaluation of a smartphone application that supports the co-creation process of \#TheDay, a UGV-driven TV format that is aired twice a week as part of a daily infotainment show and that has been included in the broadcast schedule for almost one year now. Via \# The Day's dedicated smartphone application, producers elicit specific contributions from the audience, based on the trending topics of that day. Using \#TheDay as a lens and by wielding a mixed methods approach, we have formulated three design considerations to facilitate long-term viewer as well as professional producer commitment in participatory media contexts. These design considerations can be summarized as follows: (i) foster intrinsic motivation factors, (ii) invest in social collaboration and even competition, and (iii) promote a conversational approach, either through personal or automated contact, as it contributes positively to user engagement.

As part of future work, we will explore the role of gamification strategies, which have already been studied quite extensively in other domains (e.g., education [2], healthcare [6]), as a stimulating means to increase audience involvement and to contribute to the establishment of co-creation communities. Secondly, based on existing \#TheDay conversational data, we will more deeply study how chatbots can alleviate the work of producers by suggesting or even automatically giving constructive feedback to users on the generation of videos and content. Finally, we will investigate opportunities to involve the UGV community in the post-production editing process.

Acknowledgments This project has received funding from the European Union's Horizon 2020 research and innovation programme under grant agreement No 761802. Maarten Wijnants is funded through a VLAIO Innovation Mandate (project number HBC.2016.0625), co-sponsored by Androme.

\section{References}

1. Tom Bartindale, Guy Schofield, Clara Crivellaro, and Peter Wright. 2016. TryFilm: Situated Support for Interactive Media Productions. In Proceedings of the 19th ACM Conference on Computer-Supported Cooperative Work \& Social Computing (CSCW '16), 1412-1422. https://doi.org/10.1145/2818048.2819929 
2. Centre for Information on Media (CIM) in Belgium. Daily report of number of viewers. Retrieved from https://www.cim.be/nl/televisie/openbare-resultaten

3. José van Dijck and Thomas Poell. 2013. Understanding Social Media Logic. Media and Communication 1, 1:2-14. https://doi.org/10.17645/mac.vli1.70

4. David Geerts, Rinze Leenheer, Dirk De Grooff, Joost Negenman, and Susanne Heijstraten. 2014. In front of and behind the second screen: viewer and producer perspectives on a companion app. In Proceedings of the 2014 ACM international conference on Interactive experiences for TV and online video - TVX '14, 95-102. https://doi.org/10.1145/2602299.2602312

5. David Philip Green, Simon J. Bowen, Christopher Newell, Guy Schofield, Tom Bartindale, Clara Crivellaro, Alia Sheikh, Peter Wright, and Patrick Olivier. 2015. Beyond Participatory Production: Digitally Supporting Grassroots Documentary. In Proceedings of the 33rd Annual ACM Conference on Human Factors in Computing Systems (CHI '15), 3157-3166. https://doi.org/10.1145/2702123.2702203

6. Asa Kroon. 2017. More than a Hashtag: Producers' and Users' Co-creation of a Loving "We" in a Second Screen TV Sports Production. Retrieved January 31, 2019 from https://journals.sagepub.com/doi/abs/10.1177/1527476417699708

7. Guy Schofield, Tom Bartindale, and Peter Wright. 2015. Bootlegger: Turning Fans into Film Crew. In Proceedings of the 33rd Annual ACM Conference on Human Factors in Computing Systems (CHI '15), 767-776. https://doi.org/10.1145/2702123.2702229

8. Sven Stollfuß. 2018. Between television, web and social media: On social TV, About:Kate and participatory production in German Public Television. Participations: Journal of Audience \& Reception Studies, 15(1). 15, 1: 24.

9. Marleen te Walvaart, Hilde Van den Bulck, and Alexander Dhoest. 2018. Engaging the Audience in a Digitised Television Production Process. Journalism Practice 12, 7: 901-917. https://doi.org/10.1080/17512786.2017.1343093 